\title{
Preoperative retrolisthesis as a risk factor of postdecompression lumbar disc herniation
}

\author{
Shota Takenaka, MD, Kosuke Tateishi, MD, PhD, Noboru Hosono, MD, PhD, \\ Yoshihiro Mukai, MD, PhD, and Takeshi Fuji, MD, PhD \\ Orthopaedic Surgery, Japan Community Healthcare Organization Osaka Hospital, Osaka, Japan
}

OBJECT In this study, the authors aimed to identify specific risk factors for postdecompression lumbar disc herniation (PDLDH) in patients who have not undergone discectomy and/or fusion.

METHODS Between 2007 and 2012, 493 patients with lumbar spinal stenosis underwent bilateral partial laminectomy without discectomy and/or fusion in a single hospital. Eighteen patients (herniation group [H group]: 15 men, 3 women; mean age 65.1 years) developed acute sciatica as a result of PDLDH within 2 years after surgery. Ninety patients who did not develop postoperative acute sciatica were selected as a control group (C group: 75 men, 15 women; mean age 65.4 years). Patients in the $\mathrm{C}$ group were age and sex matched with those in the $\mathrm{H}$ group. The patients in the groups were also matched for decompression level, number of decompression levels, and surgery date. The radiographic variables measured included percentage of slippage, intervertebral angle, range of motion, lumbar lordosis, disc height, facet angle, extent of facet removal, facet degeneration, disc degeneration, and vertebral endplate degeneration. The threshold for PDLDH risk factors was evaluated using a continuous numerical variable and receiver operating characteristic curve analysis. The area under the curve was used to determine the diagnostic performance, and values greater than 0.75 were considered to represent good performance.

RESULTS Multivariate analysis revealed that preoperative retrolisthesis during extension was the sole significant independent risk factor for PDLDH. The area under the curve for preoperative retrolisthesis during extension was 0.849; the cutoff value was estimated to be a retrolisthesis of $7.2 \%$ during extension.

CONCLUSIONS The authors observed that bilateral partial laminectomy, performed along with the removal of the posterior support ligament, may not be suitable for lumbar spinal stenosis patients with preoperative retrolisthesis greater than $7.2 \%$ during extension.

http://thejns.org/doi/abs/10.3171/2015.6.SPINE15288

KEY WORDS complication; disc herniation; laminectomy; retrolisthesis; lumbar

$\mathrm{B}$ ILATERAL partial laminectomy (BPL) is a widely accepted procedure for the treatment of patients with lumbar spinal canal stenosis (LSS) without any instability or anterolisthesis. Although most LSS patients show significant neurological gain and good clinical courses after lumbar posterior decompression, including BPL, ${ }^{8,38}$ some patients experience a recurrence of acute limb pain in the relatively early postoperative period because of restenosis, instability, or disc herniation. $5,8,11,17,19,20,26,28,36,38$ In particular, postdecompression lumbar disc herniation (PDLDH) at the same level is the first or second most common reason for reoperations. ${ }^{8,11,17,19,21,36,38}$ By identifying PDLDH risk factors, it is possible to avoid reoperations at the same level, which are often complicated and even risky ${ }^{35}$ However, previous reports have included patient cohorts that were too heterogeneous to appropriately elucidate significant PDLDH risk factors. In the present study, we aimed to identify the preoperative and intraoperative risk factors for PDLDH in homogeneous patient cohorts.

\section{Methods \\ Patients}

This study was reviewed and approved by our institution's ethics committee, and informed consent was ob-

ABBREVIATIONS AUC = area under the curve; BPL = bilateral partial laminectomy; DM = diabetes mellitus; ISL = interspinous ligament; JOA = Japanese Orthopaedic Association; LSS = lumbar spinal canal stenosis; PDLDH = postdecompression lumbar disc herniation; ROC = receiver operating characteristic; ROM = range of motion; SSL = supraspinous ligament.

SUBMITTED March 10, 2015. ACCEPTED June 17, 2015.

INCLUDE WHEN CITING Published online December 11, 2015; DOI: 10.3171/2015.6.SPINE15288. 
tained from the patients. Between September 2007 and April 2012, 493 LSS patients (326 men, 167 women) with an average age of 69.7 years (range 29-90 years) underwent BPL without concomitant discectomy or fusion. None of the patients had previously undergone lumbar surgery. This cohort did not include patients with a forward slip of greater than $11 \%$ and or an intervertebral range of motion (ROM) greater than $11^{\circ}$, based on the findings of preoperative flexion-extension lateral radiographs. Preoperatively, patients received conservative treatment, which did not sufficiently relieve their pain or intermittent claudication, or experienced significant palsy that required surgery.

As shown in Fig. 1, 319 patients were eventually enrolled in the study. PDLDH was defined as acute lowerlimb pain that developed within 2 years postoperatively. Patients were included in a herniation group ( $\mathrm{H}$ group, $\mathrm{n}$ $=18$ ) if 1) newly herniated discs were observed postoperatively, and 2) MRI findings were consistent with acute lower-limb pain (Fig. 2). However, new, asymptomatic herniated discs were not considered in this definition.

The candidates for the control group (C group) included 301 patients (189 men, 112 women) with an average age of 69.8 years (range $29-90$ years). Generally, sampling 4 or 5

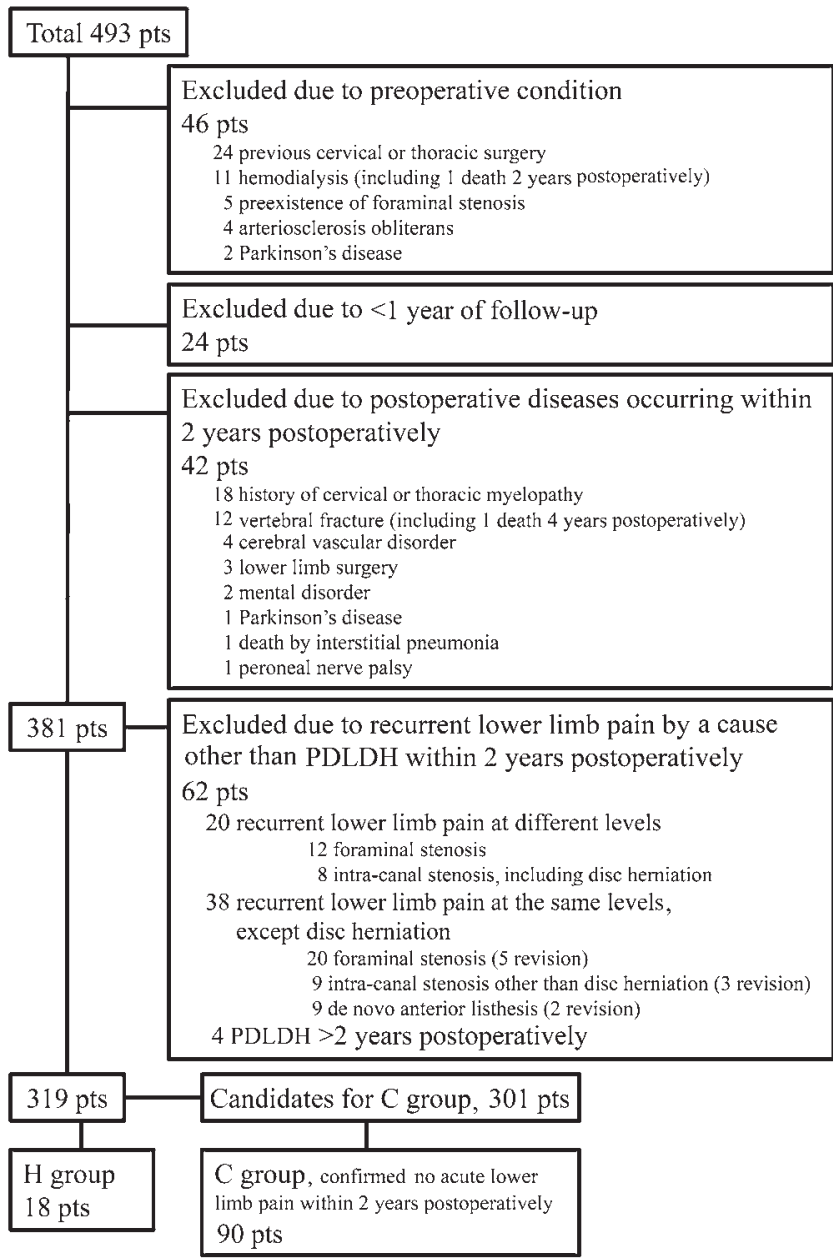

FIG. 1. Flow chart showing patient exclusion criteria. $p t s=$ patients.
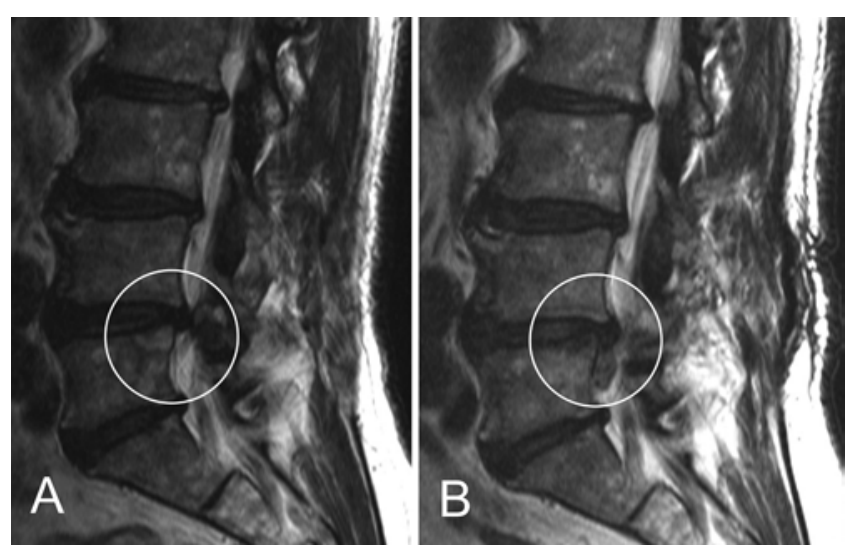

FIG. 2. Case 15. Sagittal MR images obtained preoperatively (A) and at 10 months after surgery (B), showing L4 -5 disc herniation. The white circle indicates PDLDH. The patient experienced acute lower-limb pain after the development of PDLDH.

control subjects for each case provides sufficient statistical power. ${ }^{34}$ Therefore, we selected 5 control subjects for each $\mathrm{H}$-group patient (a total of 90 patients in the $\mathrm{C}$ group).

\section{Control Group Selection}

The 90 patients in the $\mathrm{C}$ group were selected as follows. First, sex and decompression levels were matched with the H-group patients. Thereafter, patients were selected if their ages (in days) at the time of surgery were similar (within 2 years) to those of the H-group patients. Preliminarily, 5 or more control candidates were selected for each of the $18 \mathrm{H}$-group patients. However, for 2 patients in the $\mathrm{H}$ group, fewer than 5 patients were available for inclusion as control subjects. Therefore, to obtain at least 5 control subjects for each of these H-group patients, the matching age window was expanded to 7 years. Consequently, 7 and 18 control candidates, respectively, were selected for these 2 patients in the $\mathrm{H}$ group. After this initial matching, priority numbers were assigned to the control candidates according to their similarity with the H-group patients in terms of the number of decompression levels and the operation date. Finally, in cases in which the control subjects matched 2 or more H-group patients, those with higher priority numbers were exclusively selected. This selection method was not arbitrary and reduced confounding factors to the greatest extent possible. Sixty-eight of the control subjects with less than 2 years of face-to face follow-up did not have any evidence of acute lower-limb pain within 2 years postoperatively, as assessed through telephone interviews.

\section{Surgical Procedures}

BPL has been described previously. ${ }^{8}$ Briefly, to decompress the L4-5 levels, the lamina and spinous processes of the lower L-4 and upper L-5 vertebrae were removed using chisels and Kerrison clamps. In addition, the ligamentum flavum and supraspinous ligament (SSL) and interspinous ligament (ISL) of L4-5 were removed. Thereafter, BPL of other levels was performed, as necessary. Figure 3 shows a posterior view of a postoperative 3D CT image. The operations on $\mathrm{H}$ - and $\mathrm{C}$-group patients were performed by 7 


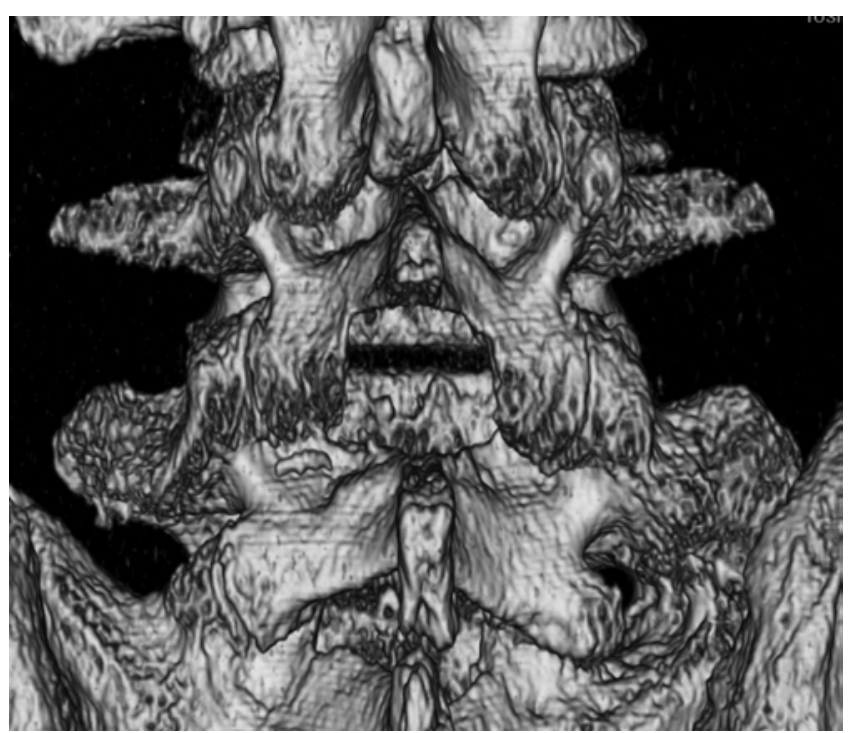

FIG. 3. 3D CT image (posterior view) acquired after BPL at L4-5. The lamina and spinous processes of the lower L-4 and upper L- 5 vertebrae were removed using a chisel and Kerrison clamp. The ligamentum flavum and SSL and ISL of $L 4-5$ were removed. BPL was also performed at other levels.

surgeons; 26 operations were performed by Surgeon A, 13 by Surgeon B, 28 by Surgeon C, 3 by Surgeon D, 25 by Surgeon E, 9 by Surgeon F, and 4 by Surgeon G.

\section{Outcomes}

All patient characteristics were recorded, including sex, age, body mass index, number of decompression levels, and distribution of decompression levels (Table 1). Vertebrae were counted from T-1 inferiorly to achieve accurate number assignment to the lumbosacral transitional vertebrae. ${ }^{23}$ Additional factors were used to compare the $\mathrm{H}$ and $\mathrm{C}$ groups, including preoperative diagnosis of diabetes mellitus (DM), preoperative Japanese Orthopaedic Association (JOA) score, ${ }^{22}$ operating time per level, and blood loss per level.

Preoperative and postoperative anteroposterior radiographs were obtained in the neutral position. Preoperative and postoperative lateral radiographs were obtained in the maximally flexed and extended positions and in the neutral position.

On anteroposterior radiographs, lateral slippage and disc wedging angle were assessed. Lateral slippage was measured using the centroid method advocated by Freedman et al. ${ }^{12}$ On lateral radiographs, the percentage of vertebral slippage during flexion in a neutral position and during extension were assessed according to the method established by Dupuis et al.7; a positive value indicated slippage in the anterior direction. The intervertebral angle during flexion (the angle made by the endplates of the disc space), extension, and ROM, and in a neutral position were also assessed; a positive value indicated lordosis. In the neutral position, lumbar lordosis between L-1 and S-1 was also measured (Fig. 4). Postoperative data were obtained 1 year postoperatively in the $\mathrm{C}$ group and in $\mathrm{H}$-group patients who developed PDLDH within 1 year postoperatively.

For 4 patients in the $\mathrm{H}$ group who underwent revision surgery, postoperative data were assessed immediately be-

TABLE 1. Patient characteristics ${ }^{*}$

\begin{tabular}{|c|c|c|c|c|c|}
\hline Characteristic & H Group & Candidates for C Group & p Value $†$ & C Group & p Valuef \\
\hline No. of patients & 18 & 301 & & 90 & \\
\hline $\mathrm{M} / \mathrm{F}$ ratio & $15: 3$ & 189:112 & 0.127 & 75:15 & 1.00 \\
\hline Mean age at op (range), yrs & $65.1 \pm 5.8(52-75)$ & $69.8 \pm 9.2(29-90)$ & 0.009 & $65.4 \pm 5.9(46-77)$ & 0.882 \\
\hline Mean BMI (range), kg/m² & $25.2 \pm 4.1(19.1-34.3)$ & $24.3 \pm 3.4(14.6-35.4)$ & 0.473 & $25.0 \pm 3.2(18.5-35.4)$ & 0.944 \\
\hline DM/non-DM ratio & $4: 14$ & - & - & $21: 69$ & 1.00 \\
\hline Mean preop JOA score (range) & $17.4 \pm 4.4(2-23)$ & - & - & $16.6 \pm 4.7(4-24)$ & 0.505 \\
\hline Mean op time per level (range), mins & $34.2 \pm 9.8(23-55)$ & - & - & $37.0 \pm 10.0(19-71)$ & 0.210 \\
\hline Mean blood loss per 1 level (range), g & $69.4 \pm 47.0(25-200)$ & - & - & $61.3 \pm 39.6(15-233)$ & 0.422 \\
\hline No. of decompression levels & & & 0.113 & & 0.480 \\
\hline 1 & 3 & 104 & & 21 & \\
\hline 2 & 7 & 118 & & 36 & \\
\hline 3 & 7 & 64 & & 26 & \\
\hline 4 & 0 & 12 & & 6 & \\
\hline 5 & 1 & 3 & & 1 & \\
\hline \multicolumn{6}{|l|}{ Decompression level } \\
\hline L1-2 & 1 & 10 & 0.478 & 3 & 0.523 \\
\hline L2-3 & 5 & 70 & 0.391 & 32 & 1.000 \\
\hline L3-4 & 12 & 182 & 0.456 & 60 & 0.786 \\
\hline L4-5 & 17 & 271 & 0.394 & 88 & 1.000 \\
\hline L5-S1 & 5 & 62 & 0.550 & 17 & 0.521 \\
\hline
\end{tabular}

$\mathrm{BMI}=$ body mass index $;-=$ not applicable.

* $p$ values in boldface indicate a statistically significant difference. Mean values are presented $\pm S D$.

$\dagger$ The $p$ value resulting from a comparison between the $H$ group and candidates for the $C$ group.

$\ddagger$ The $p$ value resulting from a comparison between the $\mathrm{H}$ and $\mathrm{C}$ groups. 

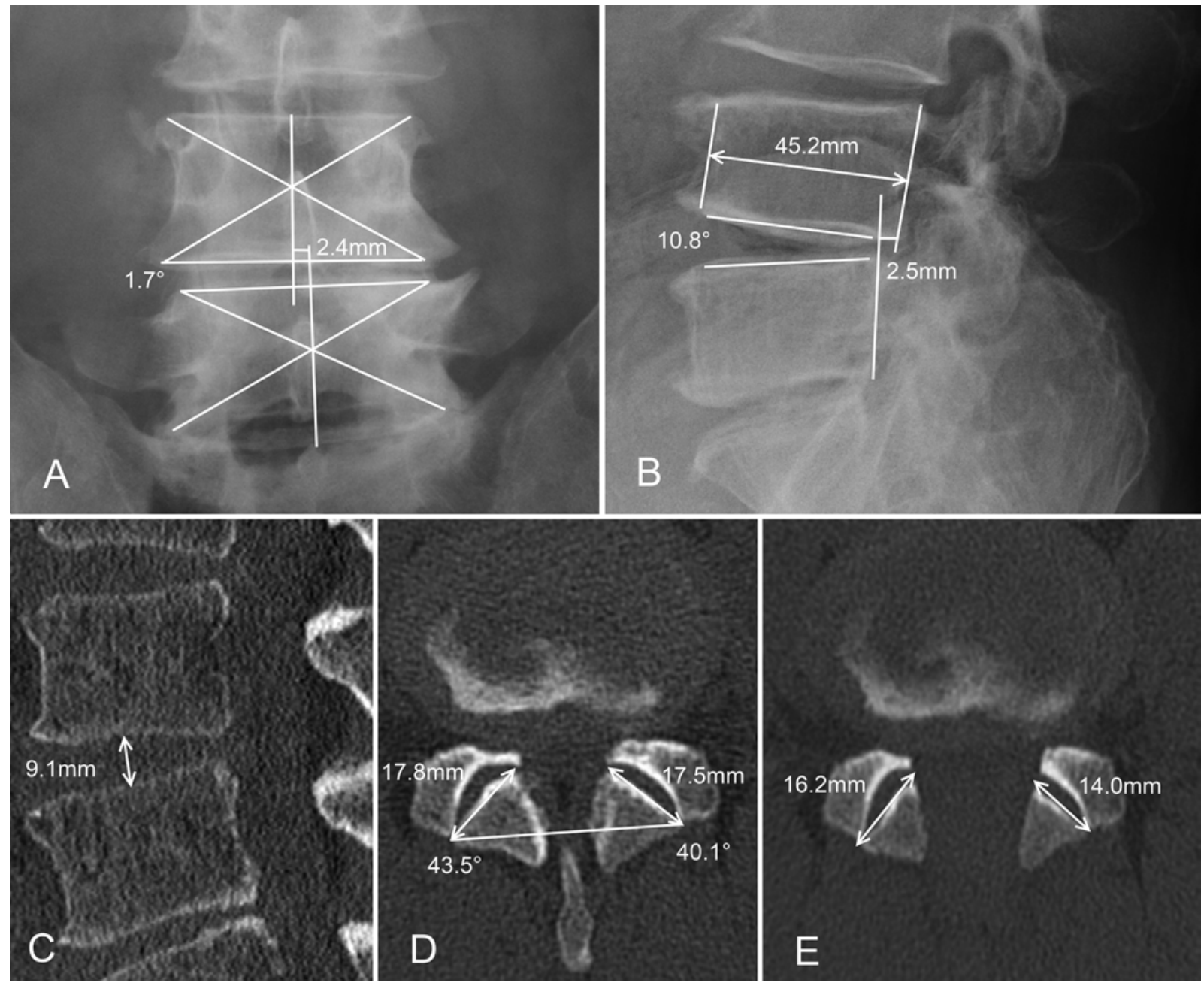

FIG. 4. Radiographs and CT images demonstrating measurement of lateral slippage, disc wedging, intervertebral and facet angles, and disc height. A: Anteroposterior digital plain radiographs were used to determine lateral slippage and disc wedging angle. B: Lateral digital plain radiographs images were used to determine percentage of slippage and intervertebral angle. C: Disc height was measured on preoperative midsagittal CT images. D and E: Preoperative (D) and postoperative (E) axial CT scans. The facet angle was measured using the angles made by connecting the 2 end points of each facet on preoperative axial CT scan (at the superior endplate level of the lower vertebra) and a line connecting the 2 dorsal points of each facet joint. The right- and left-side angles were averaged $\left(41.8^{\circ}\right.$ in this example). The extent of facet removal was calculated as a percentage based on the following formula: $100 \times$ (preoperative facet length - postoperative facet length)/preoperative facet length. The right- and left-side percentages were averaged ( $14.5 \%$ in this example).

fore revision surgery. For 5 patients in the $\mathrm{H}$ group who developed PDLDH 1-2 years postoperatively, postoperative data were assessed immediately after PDLDH diagnosis.

CT images were assessed for the following 4 parameters: disc height, ${ }^{3}$ facet joint angle, ${ }^{3}$ extent of facet removal,${ }^{14}$ and facet degeneration. ${ }^{37}$ These parameters were measured according to previously reported methods $\mathrm{s}^{3,14,37}$ (Fig. 4).

Disc degeneration and vertebral endplates were assessed using MRI. Pfirrmann classification was used to stratify disc degeneration into 5 grades, based on T2weighted midsagittal MRI cuts of the lumbar spine. ${ }^{30}$ Vertebral endplate degenerative changes were classified as normal, or Type I, II, or III using the Modic scale. ${ }^{27}$

All the radiographic, CT, and MRI evaluations were performed at the level of PDLDH for the $\mathrm{H}$ group, as well as at the corresponding level for the $\mathrm{C}$ group, except in cases of lumbar lordosis.

\section{Reproducibility Evaluation}

To evaluate intraobserver and interobserver reliability, 20 of the 108 patients were selected randomly and underwent measurement twice, with a 2-week interval, by 1 investigator (S.T.) and by a second observer (K.T.). Both observers are orthopedic spine surgeons who were blinded to the subject information. The reproducibility of numeric data were evaluated using intraclass correlation coefficients, and that of categorized data were evaluated using kappa coefficients. The interobserver intraclass correlation coefficients were calculated using the average of 2 measurements. The interobserver kappa values were cal- 
culated using the first measurement. The intraobserver and interobserver reliabilities were fully acceptable (Table 2). ${ }^{24}$

\section{Statistical Analysis}

We used SPSS statistical software version 21.0 (IBM) for all statistical analyses. To compare the 2 groups using the Mann-Whitney U-test and Fisher's exact test, $p$ values less than 0.05 were considered statistically significant. Multivariate logistic regression analysis with forward stepwise selection was performed using variables that showed $\mathrm{p}$ values less than 0.20 in the univariate analysis.

\section{Receiver Operating Characteristic Curve}

We evaluated the threshold for a potential PDLDH risk factor, described as a continuous numerical variable, using received operating characteristic (ROC) curve analyses, which plot sensitivity against the result of 1 minus the specificity. ${ }^{9}$ The area under the curve (AUC) was used to determine diagnostic performance. AUC values greater than 0.75 are generally considered to represent good performance. ${ }^{32}$ The cutoff value was determined using the Youden Index..$^{10}$

\section{Results}

\section{Patient-Group Demographics}

A total of 18 patients who developed new lumbar disc herniation at the same level postsurgically were included in the $\mathrm{H}$ group (Fig. 2). Patients in the $\mathrm{H}$ group were significantly younger than the candidates for the $\mathrm{C}$ group (Table 1). After the strict selection of control subjects, 90 patients were included in the $\mathrm{C}$ group (Table 1).
The $\mathrm{H}$ and $\mathrm{C}$ groups were comparable in terms of sex ratio, age at the time of surgery, body mass index, DM prevalence, preoperative JOA score, operative time per level, blood loss per level, number of decompression levels, and distribution of decompression levels. The H-group patient characteristics are outlined in Table 3. Revision surgery was required in $4 \mathrm{H}$-group patients; 2 underwent discectomy and 2 underwent fusion surgery. The procedures and postoperative recoveries were uneventful. No patients in the $\mathrm{C}$ group underwent revision surgery.

\section{Univariate Analysis of Pre- and Perioperative Radiologic Data}

Table 4 lists the potential predictive variables for PDLDH. Univariate analysis revealed that patients in the $\mathrm{H}$ group were more likely to have preoperative retrolisthesis and lower lumbar lordosis than those in the C group; the differences were statistically significant. In both groups, the extent of facet removal was approximately $15 \%$.

\section{Multivariate Logistic Regression Analysis}

To remove multicollinearity in multivariate logistic regression analysis, we omitted the percentage of slippage demonstrated during flexion and in the neutral position, which showed correlation coefficients greater than 0.7 with percentage of slippage during extension ( 0.821 and 0.881 by Spearman's correlation, respectively). Similarly, the intervertebral angle in the neutral position was omitted (Spearman's correlation 0.863, with the intervertebral angle during extension). Eventually, the following 5 variables were adopted as potential predictors: 1) percentage of slippage during extension, 2) intervertebral angle dur-

TABLE 2. Intraobserver and interobserver reliability

\begin{tabular}{|c|c|c|c|}
\hline \multirow[b]{2}{*}{ Radiographic Factor } & \multicolumn{2}{|c|}{ Intraobserver } & \multirow{2}{*}{$\frac{\text { Interobserver }}{\mathrm{R} 1-\mathrm{R} 2}$} \\
\hline & R1-R1 (95\% Cl) & R2-R2 (95\% Cl) & \\
\hline \multicolumn{4}{|l|}{ Plain radiography } \\
\hline AP lateral slip & $0.962(0.908-0.985)$ & $0.905(0.780-0.961)$ & $0.826(0.524-0.934)$ \\
\hline AP disc wedging angle & $0.880(0.726-0.950)$ & $0.819(0.604-0.924)$ & $0.772(0.486-0.905)$ \\
\hline Percentage of slippage (flexion) & $0.968(0.924-0.987)$ & $0.922(0.817-0.968)$ & $0.858(0.681-0.941)$ \\
\hline Percentage of slippage (neutral) & $0.958(0.899-0.983)$ & $0.903(0.775-0.960)$ & $0.875(0.716-0.948)$ \\
\hline Percentage of slippage (extension) & $0.976(0.941-0.990)$ & $0.957(0.897-0.983)$ & $0.840(0.645-0.933)$ \\
\hline Intervertebral angle (flexion) & $0.923(0.823-0.968)$ & $0.877(0.720-0.949)$ & $0.937(0.850-0.974)$ \\
\hline Intervertebral angle (neutral) & $0.889(0.751-0.953)$ & $0.838(0.642-0.932)$ & $0.880(0.727-0.951)$ \\
\hline Intervertebral angle (extension) & $0.928(0.834-0.970)$ & $0.921(0.814-0.968)$ & $0.840(0.537-0.933)$ \\
\hline Intervertebral ROM & $0.839(0.643-0.933)$ & $0.816(0.597-0.922)$ & $0.852(0.667-0.939)$ \\
\hline Lumbar lordosis at L1-S1 & $0.965(0.917--0.986)$ & $0.979(0.948-0.991)$ & $0.945(0.867-0.978)$ \\
\hline \multicolumn{4}{|l|}{ CT scanning } \\
\hline Disc height & $0.962(0.910-0.984)$ & $0.934(0.843-0.973)$ & $0.966(0.486-0.992)$ \\
\hline Facet angle & $0.985(0.964-0.994)$ & $0.913(0.797-0.964)$ & $0.898(0.708-0.962)$ \\
\hline Extent of facet removal & $0.875(0.722-0.947)$ & $0.840(0.646-0.933)$ & $0.895(0.757-0.958)$ \\
\hline Facet joint degeneration & 0.930 & 0.932 & 0.865 \\
\hline \multicolumn{4}{|l|}{ MRI } \\
\hline Disc degeneration & 0.857 & 0.692 & 0.857 \\
\hline Modic change & 1.00 & 0.649 & 1.00 \\
\hline
\end{tabular}

$\mathrm{AP}=$ anteroposterior; $\mathrm{R} 1$ and $\mathrm{R} 2=$ Reviewer 1 and 2. 
TABLE 3. Summary of the $H$ group

\begin{tabular}{|c|c|c|c|c|c|}
\hline $\begin{array}{l}\mathrm{Pt} \\
\text { No. }\end{array}$ & $\begin{array}{c}\text { Age } \\
\text { (yrs), } \\
\text { Sex }\end{array}$ & $\begin{array}{l}\text { Herniation } \\
\text { Level }\end{array}$ & $\begin{array}{c}\text { No. of } \\
\text { Decomp } \\
\text { Levels }\end{array}$ & $\begin{array}{c}\text { Onset of } \\
\text { Herniation, } \\
\text { Yrs }\end{array}$ & $\begin{array}{c}\text { Revision Op } \\
\text { (type) }\end{array}$ \\
\hline 1 & $70, \mathrm{M}$ & Lt L2-3 & 3 & 0.07 & - \\
\hline 2 & $52, \mathrm{M}$ & Rt L2-3 & 3 & 0.15 & + (discectomy) \\
\hline 3 & $66, \mathrm{M}$ & Rt L2-3 & 3 & 1.93 & - \\
\hline 4 & $62, \mathrm{M}$ & Rt L3-4 & 2 & 0.48 & - \\
\hline 5 & $64, \mathrm{M}$ & Rt L3-4 & 3 & 0.24 & + (fusion) \\
\hline 6 & $71, \mathrm{M}$ & Rt L3-4 & 2 & 1.53 & - \\
\hline 7 & $70, \mathrm{M}$ & Rt L4-5 & 2 & 0.77 & - \\
\hline 8 & $58, \mathrm{M}$ & Lt L4-5 & 3 & 0.60 & - \\
\hline 9 & $75, \mathrm{M}$ & Rt L4-5 & 3 & 1.52 & - \\
\hline 10 & $69, \mathrm{M}$ & Rt L4-5 & 1 & 0.55 & + (fusion) \\
\hline 11 & $62, \mathrm{M}$ & Cent L4-5 & 2 & 1.96 & + (discectomy) \\
\hline 12 & $68, \mathrm{~F}$ & Rt L4-5 & 1 & 0.36 & - \\
\hline 13 & $62, \mathrm{M}$ & Cent L4-5 & 2 & 0.12 & - \\
\hline 14 & $72, \mathrm{~F}$ & Rt L4-5 & 2 & 0.06 & - \\
\hline 15 & $67, \mathrm{M}$ & Rt L4-5 & 1 & 0.84 & - \\
\hline 16 & $61, \mathrm{~F}$ & Rt L4-5 & 2 & 0.35 & - \\
\hline 17 & $58, \mathrm{M}$ & Lt L4-5 & 3 & 1.98 & - \\
\hline 18 & $64, \mathrm{M}$ & Lt L5-S1 & 5 & 1.91 & - \\
\hline
\end{tabular}

Cent = central; decomp = decompression; pt = patient; - = patient underwent no revision surgery; + = patient underwent revision surgery.

ing flexion, 3) intervertebral angle during extension, 4) lumbar lordosis, and 5) facet joint degeneration. The analysis revealed that percentage of slippage during extension was the sole significant independent risk factor of PDLDH $(\mathrm{p}=0.0001 ;$ OR $1.36 ; 95 \%$ CI 1.17-1.58).

\section{ROC Curve Analysis}

The AUC for retrolisthesis during extension, which was the negated value of the percentage of slippage during extension, for PDLDH was 0.849 (95\% CI 0.755-0.943; p < $0.001)$. The cutoff value was $7.2 \%$, per the Youden Index (Fig. 5). The average vertebral anteroposterior diameter in the 108 patients was $42.6 \mathrm{~mm}$. Therefore, retrolisthesis of $7.2 \%$ corresponded to a value of $3.1 \mathrm{~mm}$. A cutoff value of $7.2 \%$ indicated an OR of 23.7 (95\% CI 6.8-82.5).

\section{Comparison of Changes Between Pre- and Postoperative Radiographic Factors}

Table 5 shows the changes in the absolute values, preand postoperatively, and radiographic factors for the patients. Patients in the $\mathrm{H}$ group demonstrated significant postoperative instability in lateral listhesis; disc wedging angle; percentage of slippage during flexion, extension, and in a neutral position; and the intervertebral angle at extension. Three patients in the $\mathrm{H}$ group developed de novo anterolisthesis postoperatively.

\section{Incidence of PDLDH Predictors for Each Surgeon}

To evaluate the influence of the surgeon, the incidence of PDLDH for each surgeon was investigated. The inci-

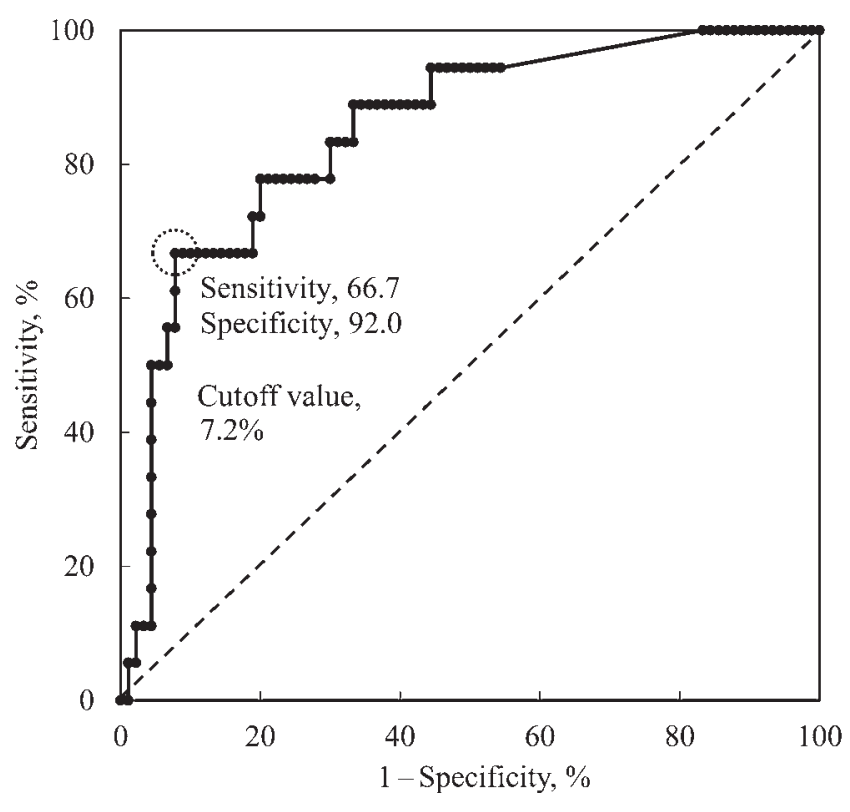

FIG. 5. ROC curve for the prediction of PDLDH within 2 years. The closer the curve approximates the left upper corner, the better the test. The straight dotted line indicates the chance results. The dotted circle indicates the cutoff point, as determined by the Youden Index.

dence was not significantly different among the 7 surgeons $(\mathrm{p}=0.394$, Fisher exact test) (Table 6).

\section{Discussion}

Many authors have investigated the clinical and radiographic results of lumbar decompression surgery and have reported certain reoperation rates and etiologies (Table 7). 5, $, 8,11,13,17,19,26,29,36,38$ In many papers, postoperative instability and lumbar disc herniation at the same level of decompression were the first or second most common reasons for reoperations. ${ }^{8,11,17,19,21,36,38}$ Given the risk of revision surgery, identifying the risk factors of PDLDH is important. However, the material or/and methods used in the previous reports were inappropriate for identifying the true risk factors of PDLDH. In many of those studies, the subjects comprised patients who did not undergo laminectomy or laminotomy alone but also underwent concomitant discectomy ${ }^{5,8,11,19,31,36}$ and/or fusion. ${ }^{11}$ In some studies, the mean follow-up period was longer than 5 years postoperatively. ${ }^{11,31,38}$ This appears to be a very long duration to extract sequelae of laminectomy or laminotomy, exclusively. Moreover, the laminectomy or laminotomy procedures varied among these studies, and some reports included several procedures. ${ }^{17,19}$ To determine the true PDLDH risk factors, we excluded patients undergoing concomitant discectomy and/or fusion during the index surgery. In addition, to minimize the aging effect, we excluded patients in whom PDLDH developed more than 2 years postoperatively. Moreover, to avoid confounding factors due to the procedures, subjects in our study included patients who underwent identical BPL surgeries.

We identified preoperative retrolisthesis as a risk factor of PDLDH within 2 years postoperatively. This result 
TABLE 4. Radiographic assessment*

\begin{tabular}{|c|c|c|c|}
\hline Radiographic Factor & H Group† & C Groupt & p Valuef \\
\hline \multicolumn{4}{|l|}{ Plain radiography } \\
\hline AP lateral slip, mm & $0.6 \pm 0.7(0-2.2)$ & $0.5 \pm 0.9(0-4.0)$ & 0.336 \\
\hline AP disc wedging angle, ${ }^{\circ}$ & $1.5 \pm 1.6(0-5.2)$ & $1.1 \pm 1.6(0-8.1)$ & 0.285 \\
\hline Percentage of slippage (flexion) & $-2.8 \pm 3.0(-9.3$ to 0$)$ & $1.0 \pm 4.5(-17.1$ to 10.9$)$ & $<0.001$ \\
\hline Percentage of slippage (neutral) & $-6.0 \pm 3.3(-11.4$ to 0$)$ & $-1.2 \pm 4.4(-12.9$ to 9.9$)$ & $<0.001$ \\
\hline Percentage of slippage (extension) & $-8.0 \pm 3.5(-14.4$ to 0$)$ & $-2.2 \pm 4.5(-18.1$ to 8.4$)$ & $<0.001$ \\
\hline Intervertebral angle (flexion), ${ }^{\circ}$ & $1.7 \pm 2.1(-2.0$ to 6.1$)$ & $0.4 \pm 3.6(-7.2$ to 10.5$)$ & 0.064 \\
\hline Intervertebral angle (neutral), ${ }^{\circ}$ & $7.6 \pm 3.8(0.2-13.3)$ & $6.2 \pm 4.4(-5.3$ to 20.2$)$ & 0.137 \\
\hline Intervertebral angle (extension), ${ }^{\circ}$ & $10.1 \pm 3.6(1.5$ to 15.5$)$ & $8.2 \pm 4.6(-0.2$ to 20.4$)$ & 0.060 \\
\hline Intervertebral ROM, ${ }^{\circ}$ & $8.4 \pm 3.7(1.8-16.3)$ & $7.8 \pm 3.4(0.9-16.3)$ & 0.510 \\
\hline Lumbar lordosis at L1-S1, $^{\circ}$ & $30.8 \pm 12.1(13.5-55.2)$ & $36.4 \pm 11.4(4.9-61.0)$ & 0.044 \\
\hline \multicolumn{4}{|l|}{ CT scanning } \\
\hline Disc height, mm & $8.7 \pm 2.4(2.2-12.4)$ & $8.0 \pm 2.8(1.0-14.0)$ & 0.262 \\
\hline Facet angle, $^{\circ}$ & $51.7 \pm 10.3(34.6-78.8)$ & $53.8 \pm 10.9(29.9-75.5)$ & 0.376 \\
\hline Extent of facet removal, $\%$ & $15.0 \pm 7.4(4.0-30.3)$ & $15.0 \pm 7.2(1.3-35.8)$ & 0.869 \\
\hline Facet joint degeneration & & & 0.126 \\
\hline Grade 0 & 3 & 5 & \\
\hline Grade 1 & 8 & 33 & \\
\hline Grade 2 & 6 & 30 & \\
\hline Grade 3 & 1 & 22 & \\
\hline \multicolumn{4}{|l|}{ MRI } \\
\hline Disc degeneration & & & 0.303 \\
\hline Grade 3 & 3 & 17 & \\
\hline Grade 4 & 15 & 61 & \\
\hline Grade 5 & 0 & 12 & \\
\hline Modic change & & & 0.839 \\
\hline Normal & 14 & 67 & \\
\hline Type I & 2 & 8 & \\
\hline Type II & 2 & 9 & \\
\hline Type III & 0 & 6 & \\
\hline
\end{tabular}

* $p$ values in boldface indicate a statistically significant difference.

† Values are presented as mean $\pm S D$ (range) or the number of patients.

$\ddagger$ The $p$ value resulting from the comparison between the $\mathrm{H}$ and $\mathrm{C}$ groups.

TABLE 5. Changes between the pre- and postoperative radiographic factors*

\begin{tabular}{|c|c|c|c|}
\hline Radiographic Factor & H Group & C Group & p Value \\
\hline AP lateral listhesis, $\mathrm{mm}$ & $0.7 \pm 0.7(0-2.3)$ & $0.3 \pm 0.5(0-4.0)$ & 0.004 \\
\hline AP disc wedging angle, ${ }^{\circ}$ & $1.7 \pm 1.7(0-6.0)$ & $0.7 \pm 0.8(0-3.6)$ & 0.004 \\
\hline Percentage of slippage (flexion) & $4.0 \pm 3.7(0-14.0)$ & $1.5 \pm 1.9(0-9.4)$ & 0.001 \\
\hline Percentage of slippage (neutral) & $4.9 \pm 5.4(0-18.8)$ & $1.9 \pm 2.4(0-11.7)$ & 0.001 \\
\hline Percentage of slippage (extension) & $5.0 \pm 6.3(0.2-21.5)$ & $1.4 \pm 1.6(0-7.6)$ & 0.001 \\
\hline Intervertebral angle (flexion), ${ }^{\circ}$ & $3.0 \pm 2.6(0.2-9.6)$ & $2.1 \pm 1.6(0.1-8.7)$ & 0.248 \\
\hline Intervertebral angle (neutral), ${ }^{\circ}$ & $3.4 \pm 3.1(0.3-10.7)$ & $1.8 \pm 1.3(0-6.0)$ & 0.106 \\
\hline Intervertebral angle (extension), ${ }^{\circ}$ & $2.9 \pm 2.3(0.2-7.1)$ & $1.6 \pm 1.3(0-4.7)$ & 0.036 \\
\hline Intervertebral ROM, ${ }^{\circ}$ & $3.5 \pm 3.5(0.2-10.8)$ & $2.6 \pm 2.1(0-9.8)$ & 0.689 \\
\hline Lumbar lordosis at L1-S1, $^{\circ}$ & $4.8 \pm 3.9(0.6-14.8)$ & $4.3 \pm 3.8(0-16.9)$ & 0.499 \\
\hline
\end{tabular}


TABLE 6. Incidence of postdecompression lumbar disc herniation by surgeon*

\begin{tabular}{|c|c|c|c|c|c|c|c|}
\hline Study Group & Surgeon $\mathrm{A}$ & Surgeon B & Surgeon $\mathrm{C}$ & Surgeon D & Surgeon $\mathrm{E}$ & Surgeon $\mathrm{F}$ & Surgeon G \\
\hline $\mathrm{H}$ group & 2 & 1 & 7 & 1 & 6 & 1 & 0 \\
\hline C group & 24 & 12 & 21 & 2 & 19 & 8 & 4 \\
\hline Total & 26 & 13 & 28 & 3 & 25 & 9 & 4 \\
\hline
\end{tabular}

suggested that the presence of preoperative retrolisthesis makes patients more prone to the development of PDLDH. Through ROC curve analysis, the cutoff value of retrolisthesis was found to be $7.2 \%$, or approximately $3 \mathrm{~mm}$. This cutoff value provided an OR of 23.7 (95\% CI 6.8-82.5). The 3-mm value dovetails with the definition of retrolisthesis described in previous papers that referred to retrolisthesis. ${ }^{2,31}$

To date, retrolisthesis has been considered to be of little clinical significance, and there is much less information available about retrolisthesis than there is regarding anterolisthesis. Heuer et al. investigated the lumbar biomechanics of human cadavers, using both angulation measurements and translational measurements as the response parameters, to study forward and backward bending..$^{18}$ Their results showed that the angulation measurements were strongly related to the translational measurements. Although listhesis corresponds to intervertebral translation, we believe that lumbar biomechanical studies, using angulation measurements in forward and backward bending, can be used to understand the results of the present study. Moreover, we hypothesized a mechanism for the high frequency of PDLDH in patients with preoperative retrolisthesis.
Through biomechanical analyses, many authors indicated that forward bending of the lumbar spine is mainly restricted by the SSLs and ISLs ${ }^{15,16,25,33,39}$; the tensile strengths of these ligaments generate this resistance force. However, the spinous processes, facet joints, and intervertebral discs play important roles in restricting backward bending. ${ }^{1,15}$ Given that the intervertebral discs contribute to the restriction of backward bending, patients in the $\mathrm{H}$ group with preoperative retrolisthesis may be suggested to have had weak discs that could no longer restrain backward bending. Therefore, the spinous processes may compensate to resist backward bending. Thus, the $\mathrm{H}$ group showed significantly more postoperative instability than the $\mathrm{C}$ group. Although the determination of whether instability or PDLDH occurred first may be impossible, removing the inferior halves of the cranial spinous processes, the SSLs and ISLs, during surgery might trigger postoperative instability or/and disc herniation. Moreover, a finite element model study by Zander et al. showed that resection of the posterior bony or ligamentous elements influences the stresses and deformations in the intervertebral discs. ${ }^{39}$

As shown in Table 7, the incidence of PDLDH was lower for the minimally invasive surgeries in which the SSLs and ISLs were preserved than for conventional open

TABLE 7. Studies with 50 or more patients who underwent lumbar decompression surgery and included reoperation descriptions

\begin{tabular}{|c|c|c|c|c|c|c|c|c|c|}
\hline Authors \& Year & Op & $\begin{array}{c}\text { Posterior } \\
\text { Element } \\
\text { Preservation }\end{array}$ & $\begin{array}{l}\text { No. of } \\
\text { Pts }\end{array}$ & $\begin{array}{l}\text { PDLDHs } \\
\text { Requiring } \\
\text { Additional } \\
\text { Op* }^{*}\end{array}$ & $\begin{array}{l}\text { No. of PDLDHs } \\
\text { Including } \\
\text { Conservative } \\
\text { Treatment* }\end{array}$ & $\begin{array}{l}\text { Postop } \\
\text { Instability } \\
\text { Requiring } \\
\text { Fusion* }\end{array}$ & $\begin{array}{l}\text { Concomitant } \\
\text { Discectomy* }\end{array}$ & $\begin{array}{c}\text { Concomitant } \\
\text { PLF }\end{array}$ & $\begin{array}{c}\text { Mean } \\
\text { FU (yrs) }\end{array}$ \\
\hline Present study & $\mathrm{BPL}$ & No & 381 & $4(1.0)$ & $18(4.7)$ & $7(1.8)$ & No & No & 2.1 \\
\hline Eule et al., 1999 & $\mathrm{BPL}$ & No & 138 & $2(1.4)$ & ND & $2(1.4)$ & $40(29)$ & No & 3.5 \\
\hline Yuzawa, 2011 & $\mathrm{BPL}$ & No & 63 & $1(1.6)$ & ND & $2(3.2)$ & ND & No & 5.0 \\
\hline Hopp \& Tsou, 1988 & $\mathrm{LN} \dagger$ & No & 344 & $14(4.1)$ & ND & $16(5.5)$ & $50 \% \ddagger$ & No & ND \\
\hline Herno et al., 1993 & $\mathrm{LN} \dagger$ & No & 108 & $2(1.9)$ & ND & $2(1.9)$ & ND & No & 12.8 \\
\hline Tuite et al., 1994 & $\mathrm{LN}$ & No & 324 & $10(3.1)$ & ND & $0(0.0)$ & 38 & No & 4.6 \\
\hline Fox et al., 1996 & $\mathrm{LN}$ & No & 124 & $3(2.4)$ & ND & $7(5.6)$ & $14(11)$ & $\begin{array}{c}\text { Yes }(n=32 \\
11 \%)\end{array}$ & 5.8 \\
\hline Fu et al., 2008 & LF & Yes & 76 & $0(0.0)$ & ND & $0(0.0)$ & ND & No & 3.3 \\
\hline Cavuşoğlu et al., 2007 & ULBD & Yes & 100 & $0(0.0)$ & ND & $0(0.0)$ & $13(13)$ & No & 5.4 \\
\hline Castro-Menéndez et al., 2009 & MEL & Yes & 50 & $0(0.0)$ & ND & $2(4.0)$ & $20(40)$ & No & 4.0 \\
\hline Pao et al., 2009 & MEL & Yes & 53 & $0(0.0)$ & ND & $0(0.0)$ & ND & No & 1.3 \\
\hline Minamide et al., 2013 & MEL & Yes & 310 & ND & $4(1.3)$ & $3(1.0)$ & ND & No & 2.0 \\
\hline
\end{tabular}

$\mathrm{FU}$ = follow-up; $\mathrm{LF}$ = laminoforaminotomy; $\mathrm{LN}$ = laminectomy; $\mathrm{MEL}$ = microendoscopic laminotomy; $\mathrm{ND}$ = not described; PLF = posterolateral fusion; ULBD = unilateral approach for bilateral decompression, under the microscope.

* Data given as number (\%) unless otherwise indicated.

$\dagger$ Mainly laminectomy but including some other procedures.

$\ddagger$ The percentage is approximate; the actual value was not described. 
decompressions. However, this comparison is overly simplified because some papers included patients in whom herniation recurred and some had different lengths of follow-up. Moreover, new surgical techniques tend to underestimate the true incidence of complications. ${ }^{4}$ Fusion surgeries for patients with a retrolisthesis greater than $7.2 \%$ might, however, be considered as overtreatment. Therefore, further studies are required to better understand how to prevent PDLDH.

This study has several limitations. First, we performed a case-control study with retrospective data collection. We believe that a nested case-control study with prospective data collection is better. However, in this study, control subjects were strictly selected without arbitrariness, making the comparisons between the $\mathrm{H}$ and $\mathrm{C}$ groups fully acceptable. Second, whole-spine radiographic evaluations were not performed with the patients in the standing position, which could provide additional information, such as that pertaining to sagittal balance. Although information regarding sagittal balance is desirable, the results of this study, nevertheless, may be helpful for making decisions to treat LSS patients. Third, although the H group strictly included patients who experienced postoperative pain remission, followed by the recurrence of lower-limb pain with consistent "new" herniation on MRI, there may be many factors that determine whether a disc herniation is symptomatic or not. This may lead to a Type 1 error.

\section{Conclusions}

This study revealed that preoperative retrolisthesis was the sole significant risk factor for PDLDH. Lumbar decompression surgery involving the removal of the posterior elements may not be suitable to prevent PDLDH. This is the first study to elucidate the significant risk factors for PDLDH.

\section{References}

1. Adams MA, Dolan P, Hutton WC: The lumbar spine in backward bending. Spine (Phila Pa 1976) 13:1019-1026, 1988

2. Berlemann U, Jeszenszky DJ, Bühler DW, Harms J: Mechanisms of retrolisthesis in the lower lumbar spine. A radiographic study. Acta Orthop Belg 65:472-477, 1999

3. Blumenthal C, Curran J, Benzel EC, Potter R, Magge SN, Harrington JF Jr, et al: Radiographic predictors of delayed instability following decompression without fusion for degenerative grade I lumbar spondylolisthesis. J Neurosurg Spine 18:340-346, 2013

4. Carragee EJ, Hurwitz EL, Weiner BK: A critical review of recombinant human bone morphogenetic protein-2 trials in spinal surgery: emerging safety concerns and lessons learned. Spine J 11:471-491, 2011

5. Castro-Menéndez M, Bravo-Ricoy JA, Casal-Moro R, Hernández-Blanco M, Jorge-Barreiro FJ: Midterm outcome after microendoscopic decompressive laminotomy for lumbar spinal stenosis: 4-year prospective study. Neurosurgery 65:100-110, A12, 2009

6. Cavuşoğlu H, Kaya RA, Türkmenoglu ON, Tuncer C, Colak I, Aydin Y: Midterm outcome after unilateral approach for bilateral decompression of lumbar spinal stenosis: 5-year prospective study. Eur Spine J 16:2133-2142, 2007

7. Dupuis PR, Yong-Hing K, Cassidy JD, Kirkaldy-Willis WH: Radiologic diagnosis of degenerative lumbar spinal instability. Spine (Phila Pa 1976) 10:262-276, 1985

8. Eule JM, Breeze R, Kindt GW: Bilateral partial laminec- tomy: a treatment for lumbar spinal stenosis and midline disc herniation. Surg Neurol 52:329-338, 1999

9. Fischer JE, Bachmann LM, Jaeschke R: A readers' guide to the interpretation of diagnostic test properties: clinical example of sepsis. Intensive Care Med 29:1043-1051, 2003

10. Fluss R, Faraggi D, Reiser B: Estimation of the Youden Index and its associated cutoff point. Biom J 47:458-472, 2005

11. Fox MW, Onofrio BM, Onofrio BM, Hanssen AD: Clinical outcomes and radiological instability following decompressive lumbar laminectomy for degenerative spinal stenosis: a comparison of patients undergoing concomitant arthrodesis versus decompression alone. J Neurosurg 85:793-802, 1996

12. Freedman BA, Horton WC, Rhee JM, Edwards CC II, Kuklo TR: Reliability analysis for manual radiographic measures of rotatory subluxation or lateral listhesis in adult scoliosis. Spine (Phila Pa 1976) 34:603-608, 2009

13. Fu YS, Zeng BF, Xu JG: Long-term outcomes of two different decompressive techniques for lumbar spinal stenosis. Spine (Phila Pa 1976) 33:514-518, 2008

14. Ghogawala Z, Benzel EC, Amin-Hanjani S, Barker FG II, Harrington JF, Magge SN, et al: Prospective outcomes evaluation after decompression with or without instrumented fusion for lumbar stenosis and degenerative Grade I spondylolisthesis. J Neurosurg Spine 1:267-272, 2004

15. Gillespie KA, Dickey JP: Biomechanical role of lumbar spine ligaments in flexion and extension: determination using a parallel linkage robot and a porcine model. Spine (Phila Pa 1976) 29:1208-1216, 2004

16. Hartmann F, Janssen C, Böhm S, Hely H, Rommens PM, Gercek E: Biomechanical effect of graded minimal-invasive decompression procedures on lumbar spinal stability. Arch Orthop Trauma Surg 132:1233-1239, 2012

17. Herno A, Airaksinen O, Saari T: Long-term results of surgical treatment of lumbar spinal stenosis. Spine (Phila Pa 1976) 18:1471-1474, 1993

18. Heuer F, Schmidt H, Claes L, Wilke HJ: Stepwise reduction of functional spinal structures increase vertebral translation and intradiscal pressure. J Biomech 40:795-803, 2007

19. Hopp E, Tsou PM: Postdecompression lumbar instability. Clin Orthop Relat Res 227:143-151, 1988

20. Iguchi T, Kanemura A, Kasahara K, Kurihara A, Doita M, Yoshiya S: Age distribution of three radiologic factors for lumbar instability: probable aging process of the instability with disc degeneration. Spine (Phila Pa 1976) 28:26282633, 2003

21. Iguchi T, Kurihara A, Nakayama J, Sato K, Kurosaka M, Yamasaki K: Minimum 10-year outcome of decompressive laminectomy for degenerative lumbar spinal stenosis. Spine (Phila Pa 1976) 25:1754-1759, 2000

22. Izumida $S$, Inoue $S$ : [Assessment of treatment for low back pain.] J Jpn Orthop Assoc 60:391-394, 1986 (Jpn)

23. Konin GP, Walz DM: Lumbosacral transitional vertebrae: classification, imaging findings, and clinical relevance. AJNR Am J Neuroradiol 31:1778-1786, 2010

24. Landis JR, Koch GG: The measurement of observer agreement for categorical data. Biometrics 33:159-174, 1977

25. Lee MJ, Bransford RJ, Bellabarba C, Chapman JR, Cohen AM, Harrington RM, et al: The effect of bilateral laminotomy versus laminectomy on the motion and stiffness of the human lumbar spine: a biomechanical comparison. Spine (Phila Pa 1976) 35:1789-1793, 2010

26. Minamide A, Yoshida M, Yamada H, Nakagawa Y, Kawai M, Maio K, et al: Endoscope-assisted spinal decompression surgery for lumbar spinal stenosis. J Neurosurg Spine 19:664-671, 2013

27. Modic MT, Steinberg PM, Ross JS, Masaryk TJ, Carter JR: Degenerative disk disease: assessment of changes in vertebral body marrow with MR imaging. Radiology 166:193-199, 1988 
28. Oertel MF, Ryang YM, Korinth MC, Gilsbach JM, Rohde $\mathrm{V}$ : Long-term results of microsurgical treatment of lumbar spinal stenosis by unilateral laminotomy for bilateral decompression. Neurosurgery 59:1264-1270, 2006

29. Pao JL, Chen WC, Chen PQ: Clinical outcomes of microendoscopic decompressive laminotomy for degenerative lumbar spinal stenosis. Eur Spine J 18:672-678, 2009

30. Pfirrmann CW, Metzdorf A, Zanetti M, Hodler J, Boos N: Magnetic resonance classification of lumbar intervertebral disc degeneration. Spine (Phila Pa 1976) 26:1873-1878, 2001

31. Shen M, Razi A, Lurie JD, Hanscom B, Weinstein J: Retrolisthesis and lumbar disc herniation: a preoperative assessment of patient function. Spine J 7:406-413, 2007

32. Swets JA: Measuring the accuracy of diagnostic systems. Science 240:1285-1293, 1988

33. Tai CL, Hsieh PH, Chen WP, Chen LH, Chen WJ, Lai PL: Biomechanical comparison of lumbar spine instability between laminectomy and bilateral laminotomy for spinal stenosis syndrome - an experimental study in porcine model. BMC Musculoskelet Disord 9:84, 2008

34. Taylor JM: Choosing the number of controls in a matched case-control study, some sample size, power and efficiency considerations. Stat Med 5:29-36, 1986

35. Tormenti MJ, Maserati MB, Bonfield CM, Gerszten PC, Moossy JJ, Kanter AS, et al: Perioperative surgical complications of transforaminal lumbar interbody fusion: a singlecenter experience. J Neurosurg Spine 16:44-50, 2012

36. Tuite GF, Stern JD, Doran SE, Papadopoulos SM, McGillicuddy JE, Oyedijo DI, et al: Outcome after laminectomy for lumbar spinal stenosis. Part I: Clinical correlations. J Neurosurg 81:699-706, 1994

37. Weishaupt D, Zanetti M, Boos N, Hodler J: MR imaging and CT in osteoarthritis of the lumbar facet joints. Skeletal Radiol 28:215-219, 1999

38. Yuzawa Y: The interspinous ligament should be removed for the decompression surgery with the case of lumbar spinal canal stenosis. Arch Orthop Trauma Surg 131:753-758, 2011

39. Zander T, Rohlmann A, Klöckner C, Bergmann G: Influence of graded facetectomy and laminectomy on spinal biomechanics. Eur Spine J 12:427-434, 2003

\section{Disclosures}

Takeshi Fuji has served as a consultant for Daiichi-Sankyo and holds patents with Century Medical and Showa-Ikakogyo.

\section{Author Contributions}

Conception and design: Takenaka. Acquisition of data: Takenaka, Tateishi. Analysis and interpretation of data: Takenaka. Drafting the article: Takenaka. Critically revising the article: Hosono. Reviewed submitted version of manuscript: Mukai. Statistical analysis: Takenaka. Study supervision: Fuji.

\section{Correspondence}

Shota Takenaka, Orthopaedic Surgery, Japan Community Healthcare Organization Osaka Hospital, 4-2-78 Fukushima, Osaka 5530003, Japan. email: show@yb3.so-net.ne.jp. 